\title{
Outcome of treatment of bladder cancer: a comparison between low-volume hospitals and an oncology centre
}

\author{
R. R. de Vries $\cdot$ O. Visser $\cdot$ J. A. Nieuwenhuijzen $\cdot$ S. Horenblas $\cdot$ \\ Members of the Urological Oncology Working Group of the Comprehensive \\ Cancer Centre Amsterdam
}

Received: 3 August 2009 / Accepted: 19 January 2010 / Published online: 4 February 2010

(C) Springer-Verlag 2010

\begin{abstract}
Purpose To evaluate the effect of volume of cystectomies in the Greater Amsterdam region on postoperative outcomes.

Methods All primary bladder tumours diagnosed between 1989 and 2003 were selected from the Amsterdam Cancer Registry, a population-based cancer registry (population 3.0 million). For all patients who underwent cystectomy during 1989-2003 at 20 participating hospitals, medical records were reviewed for information on postoperative mortality, locoregional recurrences and relative risk of death. To assess the effect of volume, outcomes at an oncology centre and low-volume hospitals were compared.

Results During 1989-2003 a total of 1,185 cystectomies were performed in 20 hospitals of the Greater Amsterdam region. Postoperative mortality was $3.2 \%$. During 1989 $1997,8 \%$ of cystectomies were performed at the oncology centre, increasing to 30\% in 1998-2003. Although postoperative mortality at this centre decreased from $4.0 \%$ in 1989-1997 to $1.1 \%$ in $1998-2003$, the latter percentage was not statistically significantly different from the other hospitals during 1998-2003 (OR 0.3; $P=0.09$ ). No statistically significant difference in locoregional recurrence rate
\end{abstract}

R. R. de Vries · J. A. Nieuwenhuijzen · S. Horenblas ( $\square)$

Department of Urology,

The Netherlands Cancer Institute/Antoni

van Leeuwenhoek Hospital, Plesmanlaan 121,

1066 CX Amsterdam, The Netherlands

e-mail: s.horenblas@nki.nl

O. Visser

Comprehensive Cancer Centre Amsterdam,

Plesmanlaan 125, 1066 CX Amsterdam, The Netherlands and in the relative risk of death was observed between the oncology centre and all other hospitals combined.

Conclusions We observed a lower postoperative mortality rate in the oncology centre compared to the low-volume hospitals; however, this difference did not reach statistical significance. We could neither prove a statistically significant relation between hospital volume, local recurrence rate and survival after cystectomy. To answer the question if centralisation of cystectomies is beneficial more procedures have to be compared.

Keywords Bladder cancer - Outcome · Volume · Centralisation $\cdot$ Cystectomy

\section{Introduction}

Indicators of outcome after cystectomy (postoperative mortality, recurrence rates and complications) have been compared between high and low-volume surgeons and hospitals in the USA. High-volume surgeons and high-volume hospitals achieve superior outcomes after cystectomy for bladder cancer patients [1-11]. However, definitions and thresholds for high- and low-volume are not defined, and vary from a minimum of three to a minimum of ten. In the USA, the regionalisation of cystectomies is encouraged by a coalition of private and public purchasers of health insurance (Leapfrog group), contrary to the Netherlands [9]. Almost all studies on volume-outcome relation were performed in the USA, and describe the postoperative mortality as indicator of outcome.

This is the first study in the Netherlands comparing volume and outcome after cystectomy for bladder cancer. In recent years, a tendency to centralisation of cystectomies, although no part of a consensus policy, has taken place in 
the greater Amsterdam region. To evaluate the effects of this centralisation we compared results of an oncology centre with other regional hospitals in the region of the Comprehensive Cancer Centre Amsterdam (CCCA).

\section{Methods}

\section{Cancer registry data}

All primary bladder tumours diagnosed and treated during 1989-2003 were selected from the CCCA Registry, a population-based cancer registry with complete regional coverage (population 3.0 million). Patients treated with cystectomy were compared with bladder cancer patients treated with cystectomy at the oncology centre. As the number of annual cystectomies in the oncology centre raised from 7 to 21 between 1997 and 1998, this was chosen as cut-off point for comparison of two periods (1989-1997 and 1998-2003). Registration clerks extracted demographic data, morphology, stage (TNM) and primary treatment from detailed hospital records. We converted all TNM-data to the sixth version [12].

\section{Follow-up of vital status}

The vital status of all patients was updated by linking the cancer registry to a file derived from the national Municipal Population Registry Network comprising all legal Dutch residents who had died or emigrated, as of 1 October 1994 until 1 February 2007. The vital status of patients dying before 1 October 1994 was updated using electronic data files, covering 1988-1994, which were made available by the majority of municipal population registries and included all deceased residents irrespective of the cause of death. Completeness of follow-up of vital status is estimated to approximate $100 \%$.

\section{Active follow-up after cystectomy}

A subset of patients was defined by selecting patients from the cancer registry who underwent a cystectomy during 1989-2003. Data for 1989-1997 were collected in 2002. For that period data from two small hospitals out of 20 could not be included because one hospital refused permission to extract data from the medical records and because many patient files had been destroyed in the other. Data for 1998-2003 were collected in 2006. A supplementary data set which was extracted from the medical records included date of surgery, margins after surgery and the development and date of locoregional recurrence (i.e. recurrence in the soft tissue in the true pelvis). In the second period, the occurrence of distant metastases was also collected in order to be able to distinguish between isolated locoregional recurrences and locoregional recurrence with concomitant metastases.

Follow-up of after cystectomy was minimally 5 years for patients treated until 2002 and minimally 4 and 3 years for patients treated in 2002 and 2003, respectively.

Because active follow-up was not always done at the oncology centre, we cannot guarantee that all recurrences in patients with residence outside the region were known to our registry. Therefore, patients referred to the oncology centre but living outside of the CCCA region were not included in the analysis of locoregional recurrence and survival after cystectomy.

\section{Statistical methods}

All statistics were performed in STATA, version 9.0. The postoperative mortality was compared between the oncology centre and all other hospitals using a Cox-regression analysis, correcting for age groups $(<60,60-74,75$ years or older) and sex. The relative risk of developing a locoregional recurrence and risk of death were analysed using a Cox-regression model. The model included the following variables: sex, morphology, T-stage, $\mathrm{N}$-stage, margins, hospital type and treatment period. Kaplan-Meier survival curves were also calculated with STATA. Survival analysis after local recurrence included only patients surviving a minimum of 3 months after cystectomy.

\section{Results}

Centralisation and number of cystectomies per hospital

During 1989-2003, a total of 1,185 cystectomies were performed in the 20 hospitals of the CCCA region. Table 1 shows that between 1989 and 1997 cystectomies were performed in all hospitals, ranging from less than one to a maximum of nine cystectomies/year. Between 1998 and 2003 three hospitals performed more than ten cystectomies/ year. The annual number of cystectomies in the oncology centre increased from 7 (1989-1997) to 30 (1998-2003). In the most recent years, the proportion of patients with residence in the CCCA region that undergoes cystectomy in the oncology centre has further increased to about $30 \%$.

\section{Postoperative mortality}

The postoperative mortality ( $\leq 30$ days after cystectomy) for all hospitals combined was $3.2 \%$, but ranged from 0 to almost 10\% (Table 1). Between 1989 and 2003 the postoperative mortality was $1.8 \%$ at the oncology centre compared to $3.5 \%$ in all other hospitals combined 
Table 1 Number of cystectomies and postoperative mortality according to hospital in the region of the Comprehensive Cancer Centre Amsterdam (CCCA) during 1989-2003

\begin{tabular}{llllll}
\hline Hospital & \multicolumn{2}{l}{\begin{tabular}{l} 
Number of cystectomies \\
\cline { 2 - 3 }
\end{tabular}} & $\begin{array}{l}\text { Postoperative } \\
\text { mortality } \\
(\%)\end{array}$ & $\begin{array}{l}\text { Median } \\
\text { age (range) }\end{array}$ \\
\hline
\end{tabular}

Low volume ( $<5$ cystectomies/year)

\begin{tabular}{lcrrll} 
A & 20 & 7 & 27 & - & $68(49-83)$ \\
$\mathrm{B}$ & 3 & 5 & 8 & - & $69(60-75)$ \\
$\mathrm{D}$ & 6 & - & 6 & - & $70(68-77)$ \\
$\mathrm{E}$ & 7 & 4 & 11 & - & $65(49-72)$ \\
$\mathrm{F}$ & 46 & 25 & 71 & 2.8 & $65(31-82)$ \\
$\mathrm{G}$ & 42 & 29 & 71 & 7.0 & $70(48-85)$ \\
$\mathrm{H}$ & 38 & 28 & 66 & - & $70(39-84)$ \\
$\mathrm{I}$ & 20 & 35 & 55 & 9.1 & $65(46-85)$ \\
$\mathrm{J}$ & 21 & 13 & 34 & 2.9 & $69(49-75)$ \\
$\mathrm{L}$ & 10 & 10 & 20 & - & $69(50-75)$ \\
$\mathrm{M}$ & 18 & - & 18 & - & $69(49-81)$ \\
$\mathrm{N}$ & 23 & 5 & 28 & 3.6 & $63(38-79)$ \\
$\mathrm{O}$ & 12 & 6 & 18 & - & $66(44-77)$ \\
$\mathrm{S}$ & 29 & 25 & 54 & 3.7 & $65(37-87)$ \\
$\mathrm{T}$ & 43 & 23 & 66 & - & $61(41-84)$ \\
Subtotal & 338 & 215 & 553 & 2.8 & $67(31-87)$ \\
Medium volume (5-10 cystectomies/year) & & & & \\
$\mathrm{C}$ & 31 & 64 & 95 & 5.3 & $67(31-87)$ \\
$\mathrm{K}$ & 46 & 41 & 87 & 5.7 & $66(43-88)$ \\
$\mathrm{P}$ & 80 & 68 & 148 & 4.0 & $70(41-93)$ \\
Q & 52 & 25 & 77 & 2.6 & $62(32-78)$ \\
Subtotal & 209 & 198 & 407 & 4.4 & $68(31-93)$ \\
High volume (>10 cystectomies/year) & & & & $63(30-80)$ \\
Oncology centre & 50 & 175 & 225 & 1.8 & $66(30-93)$ \\
Total & 597 & 588 & 1,185 & 3.2 & \\
\hline
\end{tabular}

[Cox-regression analysis, correcting for age group and sex: odds ratio (OR) 0.6; $P=$ ns]. Between 1989 and 1997 postoperative mortality in the oncological centre exceeded the postoperative mortality in the other hospitals (4.0 vs. $2.9 \%$; OR 0.7; $P=$ ns), while during 1998-2003 the percentage decreased in the oncological centre to $1.1 \%$ compared to $4.4 \%$ in the other hospitals (OR 0.3; $P=0.09$ ). The median age in the oncology centre was significantly lower than in the low-volume hospitals (Table 1).

\section{Locoregional recurrence}

After exclusion of patients with residence outside the CCCA region, stage 0 patients, salvage cystectomies and cases with postoperative mortality, 926 patients remained for the analysis of local recurrence: 122 patients were operated in the oncology centre and 804 in one of the other hospitals (Table 2). 184 patients (19.9\%) developed a locoregional recurrence after cystectomy, including six, more than 5 years after cystectomy. The vast majority
(91\%) of recurrences occurred within 3 years after cystectomy, $81 \%$ within 2 years. Of the patients who underwent surgery during 1989-1997, $102(21.2 \%)$ developed a locoregional recurrence. During 1998-2003, 82 (18.4\%) patients developed a locoregional recurrence (HR 0.7, 95\% CI 0.5-0.9), including 44 (9.9\%) isolated locoregional recurrences with no evidence of concomitant distant metastases. Using the actuarial method to calculate the odds of recurrence, the rates were 25\% during 1989-1997 and 21\% during 1998-2003.

No statistically significant difference in locoregional recurrence rate was observed between the oncology centre $(18.9 \%)$ and all other hospitals combined (20\%) (HR 0.9, 95\% CI 0.5-1.4). In a sub-analysis of the second period (1998-2003), we compared the risk of isolated locoregional recurrence (i.e. in the absence of concomitant distant metastasis) between various hospital types. In high-volume hospitals (>10 cystectomies/year; three hospitals), intermediate volume (5-10; two hospitals) and low volume $(<5 ; 13$ hospitals) stratified for sex, morphology, T-stage, N-stage 
Table 2 Relative risk of locoregional recurrence following cystectomy in patients with invasive bladder cancer in the region of Comprehensive Cancer Centre Amsterdam (CCCA) during 1989-2003
$R O$ negative; $R 1$ positive;

$R X$ unknown

$* P<0.05$

\begin{tabular}{|c|c|c|c|c|}
\hline \multirow[t]{2}{*}{ Parameter } & \multirow{2}{*}{$\begin{array}{l}\text { Number of } \\
\text { cystectomies }\end{array}$} & \multirow{2}{*}{$\begin{array}{l}\text { Locoregional } \\
\text { recurrence }(\%)\end{array}$} & \multicolumn{2}{|l|}{ Hazard ratio } \\
\hline & & & $\begin{array}{l}\text { Univariate } \\
(95 \% \mathrm{CI})\end{array}$ & $\begin{array}{l}\text { Multivariate } \\
(95 \% \text { CI })\end{array}$ \\
\hline \multicolumn{5}{|l|}{ Sex } \\
\hline Males & 722 & 19.7 & 1 (Ref.) & 1 (Ref.) \\
\hline Females & 204 & 20.6 & $1.1(0.8-1.6)$ & $1.1(0.8-1.6)$ \\
\hline \multicolumn{5}{|l|}{ Morphology } \\
\hline Transitional cell ca. & 844 & 19.4 & 1 (Ref.) & 1 (Ref.) \\
\hline Squamous cell ca. & 39 & 12.8 & $0.5(0.2-1.4)$ & $0.4(0.2-1.2)$ \\
\hline Adenocarcinoma & 26 & 34.6 & $1.8(0.9-3.5)$ & $1.5(0.7-2.9)$ \\
\hline Undifferentiated ca. & 17 & 35.3 & $2.7(1.2-6.1)^{*}$ & $2.2(1.0-5.0)$ \\
\hline \multicolumn{5}{|l|}{ T-stage } \\
\hline $\mathrm{T} 1$ & 109 & 11.9 & 1 (Ref.) & 1 (Ref.) \\
\hline $\mathrm{T} 2$ & 410 & 13.9 & $1.2(0.7-2.2)$ & $1.2(0.7-2.2)$ \\
\hline $\mathrm{T} 3$ & 323 & 26.6 & $3.1(1.7-5.5)^{*}$ & $2.9(1.6-5.3)^{*}$ \\
\hline $\mathrm{T} 4$ & 84 & 33.3 & $4.7(2.4-9.1)^{*}$ & $3.9(2.0-7.7)^{*}$ \\
\hline \multicolumn{5}{|l|}{$\mathrm{N}$-stage } \\
\hline Negative & 803 & 18.2 & 1 (Ref.) & 1 (Ref.) \\
\hline Positive & 123 & 30.9 & $2.5(1.8-3.6)^{*}$ & $2.0(1.3-2.9)^{*}$ \\
\hline \multicolumn{5}{|l|}{ Margins } \\
\hline R0 & 813 & 18.5 & 1 (Ref.) & 1 (Ref.) \\
\hline $\mathrm{R} 1$ & 70 & 32.9 & $2.6(1.7-4.1)^{*}$ & $1.8(1.2-2.9)^{*}$ \\
\hline $\mathrm{RX}$ & 43 & 25.6 & $2.4(1.3-4.5)^{*}$ & $1.7(0.9-3.2)$ \\
\hline \multicolumn{5}{|l|}{ Hospital } \\
\hline Low-volume hospital & 804 & 20.0 & 1 (Ref.) & 1 (Ref.) \\
\hline Oncology centre & 122 & 18.9 & $1.0(0.7-1.6)$ & $0.9(0.5-1.4)$ \\
\hline \multicolumn{5}{|l|}{ Treatment period } \\
\hline 1989-1997 & 481 & 21.2 & 1 (Ref.) & 1 (Ref.) \\
\hline 1998-2003 & 445 & 18.4 & $0.8(0.6-1.1)$ & $0.7(0.5-0.9)^{*}$ \\
\hline Total & 926 & & & \\
\hline
\end{tabular}

the relation between volume and short term outcome is strong and consistent, especially for high-risk cancer surgery $[6,13,14]$. A recent study comparing hospital characteristics between low- and high-volume hospitals in the USA showed that differences in the processes of care play an important role in postoperative mortality. Hospital capacity, staffing level, clinical services, diagnostic and interventional health services were at a considerably lower level at low-volume hospitals as compared to high-volume centres [7]. All these hospital-related differences influence morbidity and postoperative mortality. Despite this evidence, the underlying mechanisms of the volume outcome relation still remain unclear [7,9]. This is further illustrated by Dutch studies comparing survival after surgery for oesophageal and pancreatic cancer in low- and high-volume hospitals, showing contradictory results [15-17].

The minimum number of cystectomies one should perform to achieve the best outcome is difficult to determine. Neither the literature nor this study can answer this question. In this study, the total number of cystectomies was 
analysed, not the number of cystectomies per surgeon. Others have tried to determine the optimum caseload per surgeon. In the UK, an optimum cut-off value of eight cystectomies per year per surgeon was found [1]. However, cut-off values for low- and high-volume hospitals and surgeons seem arbitrary and vary in different studies $[1,5,8,9$, 11]. With a mortality rate between 0.5 and $5.5 \%$ and a morbidity rate from 22 to $57 \%$, cystectomy is considered a high-risk procedure [18]. These findings have led to centralisation of such procedures in the USA $[9,19]$. Although no part of a consensus policy in the greater Amsterdam region, there seems to be a tendency to centralisation, demonstrated by the rise in the annual percentage of cystectomies performed at the oncology centre in relation to the total number of cystectomies. Especially between 1997 and 1998, the annual number of cystectomies rose from 7 to 21 and increased to 30 from that moment on. This swift increase was the result of the expansion of the urology department in the oncology centre. At this moment, 30\% of cystectomies in the Greater Amsterdam region and almost $10 \%$ of the total number of cystectomies in the Netherlands is being performed at the oncology centre.

\section{Postoperative mortality}

We found an overall postoperative mortality of $3.2 \%$ in range with most recent studies $(0.5-5.5 \%)[9,13,14,19-22]$. Like in most studies, we observed a lower postoperative mortality rate in the oncology centre compared to other hospitals, especially in the second period of our study, after an increase of annual cystectomies, although this difference was not statistically significant.

The median age at cystectomy was lower in the oncology centre as compared to the other hospitals. While this may cause better outcome figures, the relation between age and postoperative mortality in cystectomy is not so strong as compared to gastric and oesophageal cancer procedures [15-17]. Recently, May et al. [23] compared the outcomes of patients younger than 75 years and older than 75 years at the time of cystectomy. They found no difference in perioperative mortality [23]. Other reports confirm their findings $[24,25]$. Comorbidity could be of utmost importance [21]. However, in this populationbased comparison between the two hospital types comorbidity should not play a role, because one would expect that comorbidity is equally distributed between all bladder cancer patients in the CCCA region treated with cystectomy. However, if selective referral of patients with more comorbidity from community hospitals to the oncology centre occurred (as we expect), then the postoperative mortality would be higher in the centre. In contrast, the postoperative mortality was lower in the centre as compared to the community hospitals.
In three other hospitals also more than ten cystectomies/ year were performed, and these hospitals might be categorised as high volume according to the literature [6]. In two out of these three hospitals, postoperative mortality remained the same during the whole study period. In the oncology centre, a lower postoperative mortality was seen for the second period when 30 cystectomies/year were performed. Many changes were introduced at the oncology centre after the first period, including standardised postoperative care, direct postoperative enteral feeding and no bowel preparation. Whether these changes are responsible for the difference can only be assessed by in depth analysis of hospital- and surgeon-related factors, which is beyond the scope of this analysis.

\section{Local recurrence and survival after cystectomy}

Differences in definition of local recurrence make it hard to compare recurrence rates between studies [26]. We found an isolated local recurrence rate of $10 \%$ in range with most reports $(4-25 \%)[27,28]$. When we look at the overall local recurrence rate with concomitant distant metastases, this percentage was $19.7 \%$. In patients with a T3 or T4 tumour, the local recurrence rate was even higher, 26.6 and $33.3 \%$, respectively.

A 3\% reduction in overall local recurrence rate was observed between the first and second periods (HR 0.7, $0.5-0.9)$. Perioperative chemotherapy (3.3\% of patients during 1989-1997; 6.5\% of patients during 1998-2003) might have influenced the risk of developing a local recurrence in our series. However, because only a few patients (32 neoadjuvants, 14 adjuvants) received this treatment, no separate analysis was possible.

In the second period, more patients with stage IV bladder cancer were treated with chemotherapy only instead of cystectomy which might explain the lower locoregional recurrence rate after cystectomy in the second period. Stage migration between the first and second periods might play an additional role in the lower locoregional recurrence rate in the second period. In the second period, the number of stage III/IV patients increased due to better staging modalities. When correcting the locoregional recurrence rate for stage in the Cox-regression model, the overall (all stages) recurrence rate decreased because of better stratification in the various stages.

We found no significant difference between the oncology centre and the other hospitals regarding the risk of developing local recurrence. When we compared low $(<5$ cystectomies/year), intermediate (5-10 cystectomies/year) and high-volume hospitals (>10 cystectomies/year), again no significant difference on local recurrence was observed.

In contrast to the comparison of short-term outcomes after cystectomy, there is only one study that reports of the 
association between volume (hospital or surgeon) and longterm outcome. No significant relation between urologist (low volume) and urologic oncologist (high volume) and risk of local recurrence after cystectomy was found [10]. One of the limitations of our study is that we do not have information about the number of cystectomies per surgeon. Volume-related differences in survival after cystectomy are small compared to other cancer surgery, so large numbers of patients are needed to find a difference [6]. Just recently a study was published comparing low- and high-volume hospitals and survival after cystectomy. 5-year survival rates after cystectomy between low- and high-volume hospitals were 35 and $39 \%$, respectively [6].

In theory, local recurrence and mortality might be good indirect indicators of quality of surgery because they are more likely to be dependent on the skills' and experience of the individual surgeon than on hospital-related factors [7]. Here again, with small differences, much larger number of procedures have to be compared to find statistically significant differences. In our opinion, hospital-related factors could be as important as surgeon-related factors in the case of cystectomy. Moreover, these factors are related to each other. This is underscored by the literature, showing higher number of cystectomies being done in larger (semi)academic hospitals, having more technical and personal resources.

\section{Conclusion}

We observed a lower postoperative mortality rate in the oncology centre compared to the low-volume hospitals, but this difference did not reach statistical significance. We could neither prove a statistical significant relation between hospital volume, local recurrence rate and survival after cystectomy. More procedures have to be compared to prove or refute the advantages of centralisation of cystectomy.

Conflict of interest statement There is no conflict of interest.

\section{References}

1. McCabe JE, Jibawi A, Javle PM (2007) Radical cystectomy: defining the threshold for a surgeon to achieve optimum outcomes. Postgrad Med J 83:556-560

2. Hollenbeck BK, Dunn RL, Miller DC et al (2007) Volume-based referral for cancer surgery: informing the debate. J Clin Oncol 25:91-96

3. Allareddy V, Allareddy V, Konety BR (2007) Specificity of procedure volume and in-hospital mortality association. Ann Surg 246:135-139

4. Skinner EC, Stein JP, Skinner DG (2007) Surgical benchmarks for the treatment of invasive bladder cancer. Urol Oncol 25:6671
5. Konety BR, Allareddy V, Modak S, Smith B (2006) Mortality after major surgery for urologic cancers in specialized urology hospitals: are they any better? J Clin Oncol 24:2006-2012

6. Birkmeyer JD, Sun Y, Wong SL, Stukel TA (2007) Hospital volume and late survival after cancer surgery. Ann Surg 245:777-783

7. Hollenbeck BK, Daignault S, Dunn RL et al (2007) Getting under the hood of the volume-outcome relationship for radical cystectomy. J Urol 177:2095-2099

8. Elting LS, Pettaway C, Bekele BN et al (2005) Correlation between annual volume of cystectomy, professional staffing, and outcomes: a statewide, population-based study. Cancer 104:975984

9. Birkmeyer JD, Siewers AE, Finlayson EV et al (2002) Hospital volume and surgical mortality in the United States. N Engl J Med 346:1128-1137

10. Herr HW, Faulkner JR, Grossman HB et al (2004) Surgical factors influence bladder cancer outcomes: a cooperative group report. J Clin Oncol 22:2781-2789

11. Black PC, Brown GA, Dinney CP (2006) Should cystectomy only be performed at high-volume hospitals by high-volume surgeons? Curr Opin Urol 16:344-349

12. Wittekind C, Greene FL, Henson DE, Hutter RVP, Sobin LH (2002) TNM classification of malignant tumours. Wiley-Liss

13. Quek ML, Stein JP, Daneshmand S et al (2006) A critical analysis of perioperative mortality from radical cystectomy. J Urol 175:886-889

14. Barbieri CE, Lee B, Cookson MS et al (2007) Association of procedure volume with radical cystectomy outcomes in a nationwide database. J Urol 178:1418-1421

15. Verhoef C, van de Weyer R, Schaapveld M, Bastiaannet E, Plukker JT (2007) Better survival in patients with esophageal cancer after surgical treatment in university hospitals: a plea for performance by surgical oncologists. Ann Surg Oncol 14:1678-1687

16. van Heek NT, Kuhlmann KF, Scholten RJ et al (2005) Hospital volume and mortality after pancreatic resection: a systematic review and an evaluation of intervention in the Netherlands. Ann Surg 242:781-788, discussion

17. van Oost FJ, Luiten EJ, van de Poll-Franse LV, Coebergh JW, van den Eijnden-van Raaij AJ (2006) Outcome of surgical treatment of pancreatic, peri-ampullary and ampullary cancer diagnosed in the south of The Netherlands: a cancer registry based study. Eur J Surg Oncol 32:548-552

18. Konety BR, Allareddy V, Herr H (2006) Complications after radical cystectomy: analysis of population-based data. Urology 68:58-64

19. Hollenbeck BK, Taub DA, Miller DC et al (2005) The regionalization of radical cystectomy to specific medical centres. J Urol 174:1385-1389

20. Shabsigh A, Korets R, Vora KC et al (2009) Defining early morbidity of radical cystectomy for patients with bladder cancer using a standardized reporting methodology. Eur Urol 55(1):164-174

21. Fairey A, Chetner M, Metcalfe J et al (2008) Associations among age, comorbidity and clinical outcomes after radical cystectomy: results from the Alberta Urology Institute radical cystectomy database. J Urol 180:128-134

22. Ghoneim MA, bdel-Latif M, el-Mekresh M et al (2008) Radical cystectomy for carcinoma of the bladder: 2,720 consecutive cases 5 years later. J Urol 180:121-127

23. May M, Fuhrer S, Braun KP et al (2007) Results from three municipal hospitals regarding radical cystectomy on elderly patients. Int Braz J Urol 33:764-773

24. Clark PE, Stein JP, Groshen SG et al (2005) Radical cystectomy in the elderly: comparison of clinical outcomes between younger and older patients. Cancer 104:36-43 
25. Gupta NP, Goel R, Hemal AK et al (2004) Radical cystectomy in septuagenarian patients with bladder cancer. Int Urol Nephrol 36:353-358

26. Quek ML, Stein JP, Clark PE et al (2004) Microscopic and gross extravesical extension in pathological staging of bladder cancer. $\mathrm{J}$ Urol 171:640-645

27. Hautmann RE, Gschwend JE, de Petriconi RC, Kron M, Volkmer BG (2006) Cystectomy for transitional cell carcinoma of the blad- der: results of a surgery only series in the neobladder era. J Urol 176:486-492

28. Madersbacher S, Hochreiter W, Burkhard F et al (2003) Radical cystectomy for bladder cancer today-a homogeneous series without neoadjuvant therapy. J Clin Oncol 21:690-696 